\title{
BMJ Open Impact of informal caregiving on older adults' physical and mental health in low-income and middle-income countries: a cross-sectional, secondary analysis based on the WHO's Study on global AGEing and adult health (SAGE)
}

Sylvie D Lambert, ${ }^{1,5}$ Steven J Bowe, ${ }^{2}$ Patricia M Livingston, ${ }^{2}$ Leila Heckel, ${ }^{2}$ Selina Cook, ${ }^{2}$ Paul Kowal, ${ }^{3,4}$ Liliana Orellana $^{2}$

To cite: Lambert SD, Bowe SJ, Livingston PM, et al. Impact of informal caregiving on older adults' physical and mental health in low-income and middle-income countries: a cross-sectional, secondary analysis based on the WHO's Study on global AGEing and adult health (SAGE). BMJ Open 2017;7:e017236. doi:10.1136/ bmjopen-2017-017236

- Prepublication history for this paper is available online. To view these files, please visit the journal online (http://dx.doi org/10.1136/bmjopen-2017017236).

Received 9 April 2017 Revised 15 July 2017 Accepted 17 August 2017

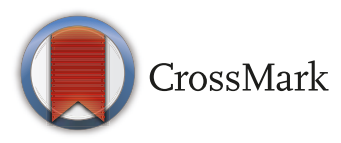

For numbered affiliations see end of article.

Correspondence to Dr Sylvie D Lambert; sylvie.lambert@mcgill.ca

\section{ABSTRACT}

Objectives A high proportion of care stemming from chronic disease or disability in low-income and middle-income countries is provided by informal caregivers. The goal of this study was to determine the level of burden experienced by these caregivers, explore associated factors and assess whether caregivers' and non-caregivers' health differed. Design and setting This cross-sectional study was a secondary analysis of data on caregivers' burden, health and health risk factors in Ghana, India and the Russian Federation collected as part of the WHO's Study on global AGEing and adult health (SAGE) Wave 1.

Participants Caregivers in Ghana $(n=143)$, India $(n=490)$ and Russia ( $n=270$ ) completed the measures.

Outcome measures Factors associated (ie, demographics and caregiving profile variables) with burden were explored among caregivers. Then, quality of life (QOL), perceived stress, depression, self-rated health (SRH) and health risk factors were compared between caregivers and matched noncaregivers (1:2).

Results The largest caregiving subgroups were spouses and adult children. Caregivers mostly cared for one person and provided financial, social/emotional and/or physical support, but received little support themselves. Burden level ranged from 17.37 to 20.03 . Variables associated with burden were mostly country-specific; however, some commonality for wealth, type of care and caregiving duration was noted. Caregivers with a moderate or high level of burden reported lower QOL and higher perceived stress than those experiencing low burden. Caregivers reported lower QOL and SRH than non-caregivers.

Conclusion Given the lack of support received and consequences of the burden endured by caregivers, policy and programme initiatives are needed to ensure that caregivers in low- and middle-income countries can fulfil their role without compromising their own health.

\section{INTRODUCTION}

Globally, the number of people aged 60 years or older is expected to grow by $56 \%$

\section{Strengths and limitations of this study}

- This is the first comprehensive study on informal caregiving burden among multiple low-income and middle-income countries.

- A key strength is that the Study on global AGEing and adult health (SAGE) has nationally representative samples, with high response rates.

- One weakness of this survey is related to its length and this time burden might have affected the quality of the responses to the caregiving-related questions, as these were the last section of the interview.

- The cross-sectional design precludes causal inferences.

between 2015 and 2030. ${ }^{1}$ This demographic shift is accompanied by a health transition, whereby $23 \%$ of the total global burden of disease is now attributable to disorders in older adults. ${ }^{2}$ Under the scenario where global prevalence of disabilities and diseases remain stable, the growth in the number of older adults alone is expected to increase demands for healthcare beyond the capacity of healthcare systems. ${ }^{3}$ Therefore, there is less reliance on specialised care settings and more focus on delivering care in the community. ${ }^{4}$ Within this context, informal caregivers provide a high proportion of the care needed and are an essential extension of the healthcare system. ${ }^{45}$ The support that caregivers provide positively impacts on care recipients' quality of life (QOL) ${ }^{6}$ and represents significant cost-saving to healthcare systems. ${ }^{4}$

Informal caregivers can be broadly defined as family members, partners, friends or neighbours who provide a wide range 
of unpaid assistance for individuals with chronic or disabling conditions. ${ }^{5}$ In high-income countries (HICs), up to almost half of the population are (or have been) a caregiver and provide anywhere from 12 to 25 hours of informal assistance per week. ${ }^{78}$ Caregivers are often responsible for specialised medical care, planning and coordinating care, monitoring patient's health status, ensuring treatment or medication adherence and preventing adverse events. ${ }^{4}$ Caregivers may also adopt the role of decision-maker, particularly if the care recipient is experiencing cognitive impairments. ${ }^{4}$ For older care recipients, caregivers typically provide assistance with activities of daily living, potentially preventing accidents and further declines in functioning. ${ }^{4}$ Emotional support is another frequent role; however, caregivers often experience the least confidence and greatest uncertainty in providing this support. ${ }^{7}$

Although caregiving is a valued societal resource and often viewed positively by caregivers themselves, caregivers remain largely a hidden and underappreciated workforce. ${ }^{9}$ Consequently, caregivers experience substantial burden, which might lead to the care recipients' institutionalisation. ${ }^{10}$ Burden is most apparent in caregivers' reporting of anxiety and depression. Depending on the caregiving profile (eg, sex, age), caregivers' prevalence of anxiety and depression can exceed general population norms, and in some cases, those reported by care recipients. ${ }^{7}$ Burden also has a negative impact on caregivers' physical health (eg, fatigue, pain), particularly as caregivers are often older themselves and confront the demands of their own illnesses. ${ }^{11}$ Further compromising their health, caregivers often prioritise the care recipients' health over their own and do not access needed support or health services ${ }^{7}$ or are less likely than non-caregivers to engage in preventive health behaviours. ${ }^{12}$ This puts caregivers' health at risk and ultimately the care recipients' health. ${ }^{13}$ With the expected growth in the number of caregivers and changes in healthcare systems as well as the substantial burden endured, the caregiving role is now considered a public health priority. ${ }^{14}$

Despite the exponential increase in the number of caregivers worldwide, few studies have examined caregivers' health in low-income and middle-income countries (LMICs) ${ }^{15}$ LMICs have a higher prevalence of disability than HICs ${ }^{16}$ and care recipients are more likely to rely on caregivers due to the governments' difficulties in financing the public healthcare system and ensuing lack of services or programmes. ${ }^{15}$ In support, Marten $e t a l^{17}$ documented as little as $1.2 \%$ of India's gross domestic product (GDP) was spent on health, while Ghana was slightly more at $3.6 \% .^{18}$ The median government health expenditure as a percentage of GDP in LMICs is estimated to be $2.0 \%$, which is in comparison to the $11 \%$ spent in Canada and $17.5 \%$ for USA. ${ }^{19-21}$ This inadvertently creates deficits in available services in LMICs, with many public health practitioners supplementing their government incomes through the privatisation of healthcare services. ${ }^{22}$ To access chronic illness care, individuals must either pay a user fee at public facilities as a means of financing the delivery of healthcare services or must use private facilities due to the inaccessibility of services through publicly funded facilities. ${ }^{23}{ }^{24}$ User fees and private services pose significant financial barriers, which leaves a significant proportion of the population in LMICs unable to access health services. ${ }^{17}$ Hence, individuals often turn to informal sources of healthcare, including their family caregivers. Within this context, it is reasonable to expect higher burden among caregivers in LMICs than those in HICs. A recent review by Thursh et al ${ }^{15}$ of 43 studies among caregivers of adults with a physical and/or mental illness in LMICs concluded that there is considerable physical, psychological, social, time and financial burden on these caregivers. Although this is highly useful data, development of this evidence base is still in its infancy. Studies published to date are limited by the small sample sizes, lack of quantitative data; diverse measures used across LMICs, limiting comparisons across countries; and few studies use a non-caregiver comparison group. Furthermore, some health consequences of caregiving on caregivers have received little to no attention in LMIC studies, including QOL, stress, depression and health risk behaviours. Therefore, there is an urgent need for more methodologically rigorous research to examine caregivers' challenges in countries other than HICs and develop an evidence base to inform policy and decision-making about health services for these caregivers.

The objectives of this population-based study were to (1) describe the caregiving profile and level of burden experienced by caregivers in two LMICs (Ghana and India) and one upper-middle country (Russian Federation), (2) examine how caregiver burden varied according to demographic and caregiving profile variables by country, (3) assess whether health-related outcomes and health risk factors are associated with caregiving burden and (4) determine the extent to which caregivers' health-related outcomes and health risk factors differed from non-caregivers by country.

\section{METHODS}

Design

This is a secondary, cross-sectional analysis of the data collected as part of the WHO's multicountry Study on global AGEing and adult health (SAGE) Wave 1 (20072010). ${ }^{25}$ SAGE was designed to collect information on the ageing process in nationally representative samples across China, Ghana, India, Mexico, the Russian Federation and South Africa.

\section{Participants}

SAGE is a representative study of the population aged 50+ in each participating country, with a smaller subsample of adults 18-49 years old. ${ }^{25}$ The methods for SAGE are extensively described elsewhere. ${ }^{25}$ In brief, multistage, stratified cluster sampling methods were used in each 
country. Country-specific strata were typically defined by region/state/province/district and locality. For all countries, a primary sampling unit (ie, enumeration areas, villages or districts) was identified to generate a list of households. Households were classified into one of two mutually exclusive categories: (1) ' $50+$ ' (older) household, where the target respondent was aged $50+$ or (2) '18-49' (younger) household, where the target respondent was aged 18-49 years. All persons aged 50+ were selected from the older households, whereas one person aged 18-49 was selected from each younger household. Poststratification weights were generated, adjusting for population distribution of age and sex in each country at the time of survey. ${ }^{26}$

The caregiver subsample comprised participants aged $50+$ who identified themselves as the primary person providing care to an adult in their household in the past 12 months. Non-caregivers were $50+$ participantswho did not provide any care to someone else in their household. Those who identified caring for someone who was deceased or a child were excluded. Data from China, Mexico and SA were not considered, because caregiving data were not collected, the caregiver subsample was too small or an extremely skewed poststratified weights distribution was observed.

\section{Data collection}

A standardised individual questionnaire was administered by trained interviewers. ${ }^{25}$ Translation of the questionnaire was led by the World Health Survey team based on the WHO guidelines (available at http://www. who.int/substance_abuse/research_tools/translation/ en/). The steps to translation included forward translation, expert panel back-translation, pretesting and final version.

\section{Demographic characteristics}

Caregivers' demographics included sex, age group, locality, marital status, household size, wealth tertile, education and employment status. Education levels were based on the international standard classification of education. ${ }^{27}$ An index of household wealth or permanent income was generated based on household ownership of durable goods, dwelling characteristics and access to services. ${ }^{28}$

\section{Caregiving profile and burden}

Caregiving profile was defined by the relationship to the care recipient, number of people cared for in the household, reasons for and types of care provided, caregiving duration and support received by the caregiver, including source. The 10-item Impact of Caregiving Scale captured the difficulties encountered by caregivers in carrying out their roles and responsibilities over the last 12 months. Each item was rated on a five-point scale ranging from $1=$ none to $5=$ extreme. Similar to another study, ${ }^{29}$ exploratory factor analysis (EFA) with oblique rotation, for each country, identified one factor (using Eigenvalue, scree plot and parallel analysis). Cronbach's alpha ranged from 0.88 to 0.93 across countries.

\section{Quality of life}

For QOL, a composite score was calculated by adding the eight items of the EUROHIS-QOL questionnaire ${ }^{30}$ and rescaling responses from 0 to 100 . The cross-cultural psychometric properties of this scale are well-documented, including unidimensionality, internal consistency (alpha range $=0.72-0.83$ across multiple countries), convergent validity with relevant physical and mental health measures and discriminant validity. ${ }^{30} 31 \mathrm{EFA}$, with oblique rotation for each country, overall found that a one-factor structure was also appropriate to use with caregivers. Cronbach's alphas in the present study were greater than 0.85 .

\section{Perceived stress}

For perceived stress, two items from the Perceived Stress Scale, rated from $0=$ never to $5=$ very often, were summed. ${ }^{32}$

\section{Depression}

Depression was assessed using the 18-item algorithm from the World Mental Health Survey version of the Composite International Diagnostic Interview. ${ }^{33}$ The diagnosis of mild, moderate and severe depression was based on the International Classification of Diseases, 10th revision (ICD-10), Classification of Mental and Behavioural Disorders, Diagnostic Criteria for Research. ${ }^{34}$ The algorithm described by Kulkarni and Shinde ${ }^{35}$ was initially used to define mild, moderate and severe depression, with mild and moderate depression combined for subsequent analyses.

\section{Self-rated health}

For self-rated health (SRH), participants answered the question: In general, how would you rate your health today? ? $^{6}$ Responses were dichotomised as 'good health' (ie, $1=$ very good, $2=$ good or 3=moderate) or 'poor health' (ie, $4=$ bad or $5=$ verybad). SRH has been found to be a reliable measure of health that is sensitive to an individual's perception of health. ${ }^{36}$

\section{Lifestyle health risk factors}

1. Body mass index (BMI) was calculated as weight $(\mathrm{kg}) /$ height $\left(\mathrm{m}^{2}\right)$ (measured by interviewer). ${ }^{37}$

2. Physical activity (PA) was determined based on participants' responses to the 16 items of the Global Physical Activity Questionnaire, an instrument with documented validity. ${ }^{38}$ Participants were asked about their activities at work, transport and leisure time, which was summarised as minutes per day of expended in moderate or vigorous PA.

3. The total number of servings of fruits and/or vegetables on an average day was calculated and classified as (1) adequate ( $\geq 4$ servings) or (2) low ( $<4$ servings)..$^{39} 40$

4. Tobacco use was categorised as (1) never used or past user of tobacco or (2) current smoker. ${ }^{41}$ 


\section{Statistical analysis}

Analyses were performed using SAS V.9.3 and graphs were created using Stata V.14.0. Unless otherwise specified, SAS survey estimation procedures were used to account for the complex, multistage probability-sampling design. Observed frequencies and sample sizes are provided for reference. The Rao-Scott $\chi^{2}$ test was used to compare the distribution of demographic characteristics between caregivers and non-caregivers and to describe the caregiving profile proportions across the variables of interest. The literature was used to identify candidate variables to explain burden. Demographic and caregiver profile variables associated with burden were identified using bivariate analyses $(p<0.25)$, followed by backward stepwise regression. Backward regression was favoured, because there are few studies that could have guided the a priori selection of covariates that would have been meaningful for each country. The final model reported for each country includes age group, sex, marital status and wealth tertile and any other factor significantly associated with burden in at least one country. Associations between burden level and health-related outcomes and risk factors were assessed using a linear or logistic regression model (including age group, sex, wealth tertile and marital status as potential confounders). To compare caregivers' and non-caregivers' health, each caregiver was matched with two non-caregivers based on country, age group, gender, marital status, wealth tertile or education level and strata. Caregivers' and non-caregivers' outcomes were compared using generalised linear models with either binary distribution and logit link for dichotomous outcomes or normal distribution and identity link for continuous outcomes (complex survey design was not considered). The pooled effect size was calculated using a random-effects model, which assumes heterogeneity among countries and the true effect can be different for each country. ${ }^{42}$

\section{RESULTS}

\section{Caregivers' demographics}

Table 1 compares the demographics of the caregivers (Ghana, $\mathrm{n}=143$; India, $\mathrm{n}=490$; Russia, $\mathrm{n}=270$ ) and non-caregivers (Ghana, $\mathrm{n}=4112$; India, $\mathrm{n}=6001$; Russia, $\mathrm{n}=3304$ ) by country. No differences based on sex and locality across countries were noted. In Ghana, caregivers were more likely to be younger, live in a large household, be wealthier, have higher education and not retired. In India, caregivers were more likely to be younger, living with a partner and in mid-size households. In Russia, living with a partner was also more frequent among caregivers than non-caregivers as well as not currently working or retired.

\section{Objective 1-Caregiving profile and level of burden}

Table 2 presents the caregiver profile by country. Across countries, caregivers mostly cared for a spouse (Russia, India) or adult children (Ghana), for health-related reasons and typically provided financial, social/emotional and/or physical support. Only in Russia did more than half of caregivers provide personal care. Up to $20 \%$ of caregivers identified receiving some kind of support to help them with their role, mostly from a family member outside the household. Across countries, the largest caregiver subgroup (40.8\%-80.7\%)\%) had been in their role for at least 6 months. The mean burden score (possible range $=10-50$ ) for caregivers in India was highest at 21.03 $(\mathrm{SE}=0.43)$, followed by Ghana at $19.32(\mathrm{SE}=0.85)$ and Russia at 17.37 ( $\mathrm{SE}=0.48)$.

\section{Objective 2-Variables associated with burden}

Table 3 presents the results of the multivariate regression analyses. Demographic and caregiving profile variables significantly associated with burden varied by country; however, some level of commonality was noted for wealth tertile, type of care and caregiving duration. In countries for which these variables were significant, caregivers reporting poorer wealth, providing health support and caring for 1-5 months were more at risk of burden. Although providing health support was not significant in Russia, a similar pattern to the other two countries was noted. However, in Russia, personal care was associated with burden.

Age and type of relationship were also significant across at least two countries, but the direction of the relationship was different. In Ghana, younger caregivers reported higher burden than their older counterparts, but the opposite was observed in Russia. Similarly, in India, being the spouse or partner was associated with higher burden, whereas in Russia this type of relationship was protective. In Russia, the subgroup of caregivers reporting higher burden based on type of relationship was the adult children.

Relationships between sex, marital status and reasons for needing care and burden were country specific. Only in Russia did women report significantly higher burden than men. In India, being without a partner was associated with higher burden. Reason for needing care was only significant in Ghana, with health-related reasons associated with higher burden.

\section{Objective 3-Burden level and caregivers' health}

Caregivers' health outcomes and health risk factors (non-weighted) are reported in figures 1 and 2 and results of the analysis of factors associated with burden (weighted analysis) in table 4. QOL scores for caregivers reporting moderate or high burden were 6-13 points lower than those reporting low burden. Caregivers experiencing moderate or high burden reported stress scores $0.67-1.26$ points higher than those reporting low burden. Burden was not significantly associated with depression or SRH.

Few associations between burden level and health risk factors were noted (table 4). In Ghana, caregivers with high burden were more likely to smoke and reported a lower BMI than those with low burden. In India, lower 


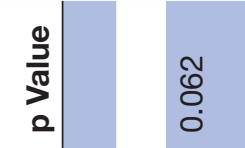

స్

लి

ส เก เก

윰 ब

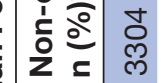

需

ญั

. ำ

एँ

$\mid$

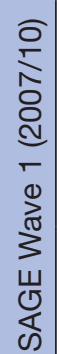

\section{Ð} ले ब्र $\infty \underset{\infty}{\infty}$

\section{न ल ल}

के

드

\section{กิ
ठ
0}

言

กั

ซึ * ช

는

ติ

हु

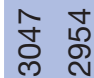

高

อ 0 o

.

言 气

กั

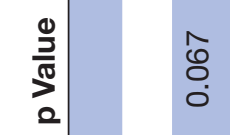

๖̀

:츠

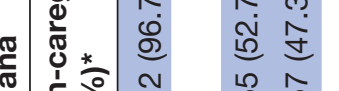

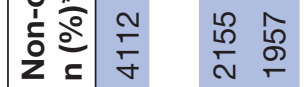

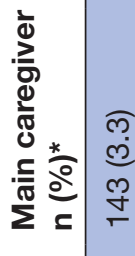

क

过苞

के के

क़ क़ ต़

过 ले

号 号

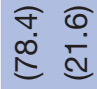

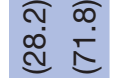

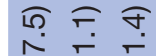

옹

กิ

लె.

ㅇ
우
v

గó

ส

ส

ฉે 옹

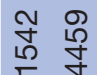

空

ผ

โด โด

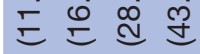

守

क ब

ले ले ल्ल

웅ㅇำ

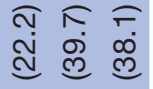

$\stackrel{\infty}{1}$ 으

กิ้

นั่

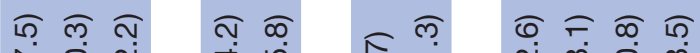

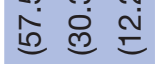

空

官

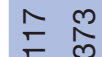

$\stackrel{8}{\circ}$

ธุ ธุ

ल्ले ल् ल्

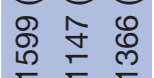

๓) ลุ

守 官

ֻٕ:

तุ

过兑

నิ నิ

สุ ธุ จ

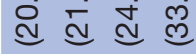

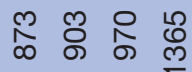

ซ ल ल

ले ले लु

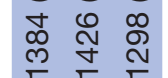

क) ก ल

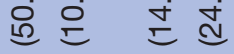

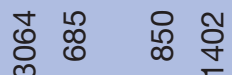

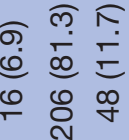

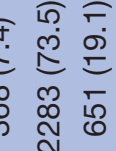

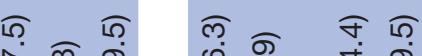

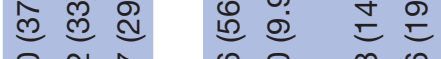

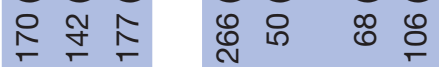

กิ
กิ

₹ 0 ₹ 0

过 लू लू बैं

-

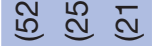

N $T$

유

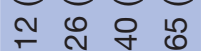

क ำ

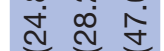

ले ले ठ

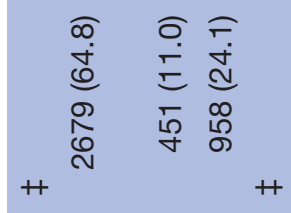

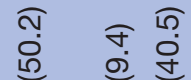

으 둔
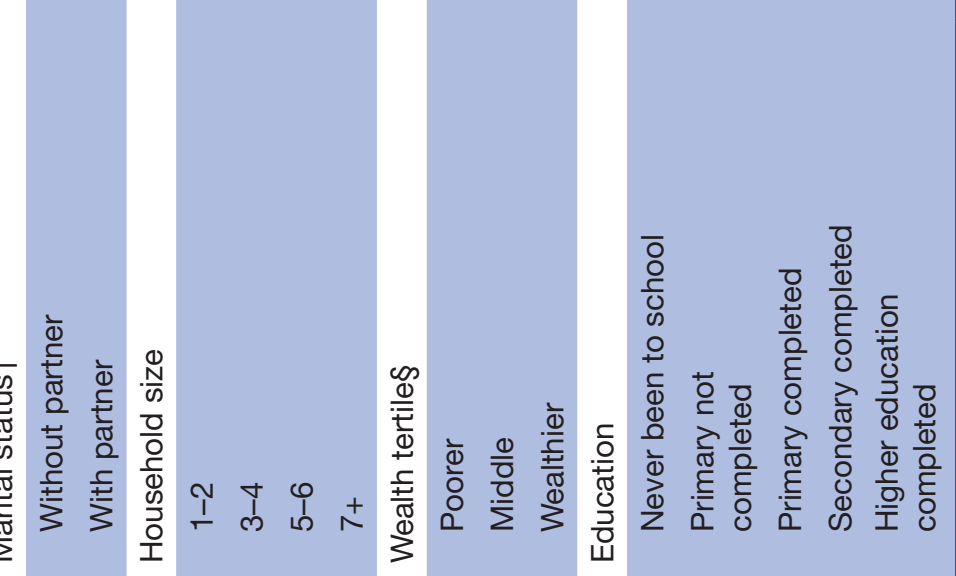
PA was noted among caregivers reporting moderate burden.

\section{Objective 4-Caregivers' and non-caregivers' health}

Across countries, caregivers in comparison to non-caregivers reported lower QOL and poorer SRH. Findings emphasised the vulnerability of caregivers in Russia, whereby they reported significantly lower QOL, more perceived stressed, depression and poorer SRH compared with non-caregivers (figure 1). None of the pooled analyses were significant for health risk factors (figure 2).

\section{DISCUSSION \\ Statement of key findings}

LMICs face higher prevalence of chronic diseases and disability than HICs. ${ }^{16}$ This, combined with limited access to formal services and programmes in LMICs, means that a high proportion of the care needed is provided by informal caregivers. ${ }^{15}$ However, studies of the burden that caregivers experience come almost exclusively from HICs. ${ }^{15}$ This lack of information, plus the growing population of older adults, suggests an urgent need for more research to examine caregivers' challenges outside HICs. The present secondary analysis described the level of burden experienced by caregivers in Ghana, India and Russia, explored associated factors and assessed whether caregivers' and non-caregivers' health differed. The key findings are: (1) few caregivers reported receiving support to help them with their role, (2) variables associated with burden were mostly country specific, but consistent with HIC studies, (3) across countries, burden has an adverse impact on caregivers' stress and QOL and (4) across countries, caregivers reported lower QOL and SRH than non-caregivers. Each key finding is discussed in turn.

\section{Comparison with other studies}

The prevalence of caregiving across countries was lower than what has been documented in HICs. This might in part be attributed to the stigma associated with some illnesses in LMICs. ${ }^{43}$ In a study by Mwinituo et al, ${ }^{43}$ caregivers of patients with AIDS reported losing their jobs because of discrimination. Another explanation for the potential lower than expected report rate is cultural expectations, as caregiving among collectivistic cultures is often deeply rooted and embedded in life experiences as an expected part of life and passed down from parent to child over many generations. ${ }^{44}$ Even participants who disclosed caring for someone in our study might have kept their caregiving role a secret from others in their community, which might explain the limited support received. Thara $e t a t^{45}$ also noted the limited support received by caregivers in India. In the present study, if caregivers did receive support, it was outside the family household, emphasising the need for external programmes. Similar to other studies, ${ }^{15}$ caregivers in this study, and particularly those in Russia, were providing a variety of time-consuming 
Table 2 Caregiving profile by country, SAGE Wave $1(2007 / 10)$

\begin{tabular}{|c|c|c|c|}
\hline & Ghana $n=143 n(\%)^{\star}$ & India $n=490 \mathrm{n}(\%)^{*}$ & $\begin{array}{l}\text { Russian Federation } \mathbf{n}=270 \\
\mathrm{n}(\%)^{*}\end{array}$ \\
\hline \multicolumn{4}{|l|}{ Types of relationship with care recipient } \\
\hline Spouse/partner & $40(29.4)$ & $291(59.1)$ & $172(57.0)$ \\
\hline Daughter/son or daughter/son in-law & $56(37.3)$ & $112(24.5)$ & $41(12.6)$ \\
\hline Parent/parent in-law & 19 (19.3) & $62(11.6)$ & $50(24.1)$ \\
\hline Other & $19(14.0)$ & $25(4.8)$ & $7(6.3)$ \\
\hline \multicolumn{4}{|c|}{ Number of people in household needing care } \\
\hline 1 & $101(73.7)$ & $434(83.8)$ & $255(96.4)$ \\
\hline 2 & $19(16.2)$ & $47(11.7)$ & $11(2.7)$ \\
\hline $3+$ & $23(10.1)$ & $9(4.5)$ & $4(0.9)$ \\
\hline \multicolumn{4}{|l|}{ Reasons for needing care } \\
\hline Health-related reason & $88(72.3)$ & $467(95.6)$ & $230(88.9)$ \\
\hline Other reason & $47(27.7)$ & $23(4.4)$ & $40(11.1)$ \\
\hline \multicolumn{4}{|l|}{ Types of care provided ${ }^{\star \star}$} \\
\hline Financial & $98(68.8)$ & $239(54.5)$ & $62(23.7)$ \\
\hline Social/Emotional & $67(51.8)$ & $252(47.3)$ & $206(72.1)$ \\
\hline Health & $62(46.6)$ & $281(63.2)$ & $88(39.7)$ \\
\hline Physical & $58(47.0)$ & $227(46.0)$ & $137(52.2)$ \\
\hline Personal care & $29(23.7)$ & $205(45.4)$ & $162(67.9)$ \\
\hline \multicolumn{4}{|l|}{ Types of personal care $\ddagger$} \\
\hline Bathing & $20(70.8)$ & $131(58.3)$ & $128(80.0)$ \\
\hline Eating & $10(33.2)$ & $127(64.9)$ & $56(33.1)$ \\
\hline Dressing & $17(60.4)$ & $100(59.1)$ & $94(59.8)$ \\
\hline Toileting & $14(49.6)$ & $112(64.5)$ & $42(20.1)$ \\
\hline Moving around & $10(39.5)$ & $110(47.7)$ & $98(56.1)$ \\
\hline Incontinence & $8(30.7)$ & $50(30.3)$ & $12(7.8)$ \\
\hline \multicolumn{4}{|l|}{ Caregiving duration } \\
\hline$<30$ days (1 month) & $16(10.5)$ & $159(34.1)$ & $54(23.2)$ \\
\hline 1 to $<6$ months & $10(8.8)$ & $118(25.1)$ & $25(7.3)$ \\
\hline$\geq 6$ months & $115(80.7)$ & $213(40.8)$ & $191(69.5)$ \\
\hline Received any kind of support (yes) & $30(24.1)$ & 77 (11.9) & $68(20.4)$ \\
\hline \multicolumn{4}{|l|}{ Support received by caregivers $\ddagger \S$} \\
\hline Financial & $25(20.2)$ & $72(11.0)$ & $31(8.0)$ \\
\hline Emotional & $4(3.2)$ & $16(2.4)$ & $45(10.9)$ \\
\hline Health & $4(4.0)$ & $10(1.6)$ & $24(4.7)$ \\
\hline Physical & $7(6.2)$ & $10(1.2)$ & $24(7.0)$ \\
\hline Personal & $2(1.8)$ & $12(1.7)$ & $21(8.7)$ \\
\hline Other & $1(0.4)$ & $1(0.02)$ & 0 \\
\hline \multicolumn{4}{|l|}{ Source of support $\ddagger$} \\
\hline Family outside household & $26(85.5)$ & $55(68.2)$ & $57(88.7)$ \\
\hline Neighbours/community & $4(13.6)$ & $33(40.4)$ & $11(12.3)$ \\
\hline Government & 0 & $3(2.4)$ & $20(14.4)$ \\
\hline Church & $2(7.8)$ & 0 & 2 (3.6) \\
\hline NGO & 0 & 0 & $2(2.7)$ \\
\hline Other & $2(5.3)$ & 0 & $3(2.7)$ \\
\hline
\end{tabular}

*Weighted \%.

${ }^{\star \star}$ For caregivers of more than one adult in the household, relationship defined in the following order, spouse, child, parent, child-in-law and parent-in-law and duration accumulated across all care recipient.

†Among those reporting providing personal care.

¥Participants answered yes/no for each option independently.

§Among those reporting receiving any type of support.

SAGE, Study on global AGEing and adult health. 


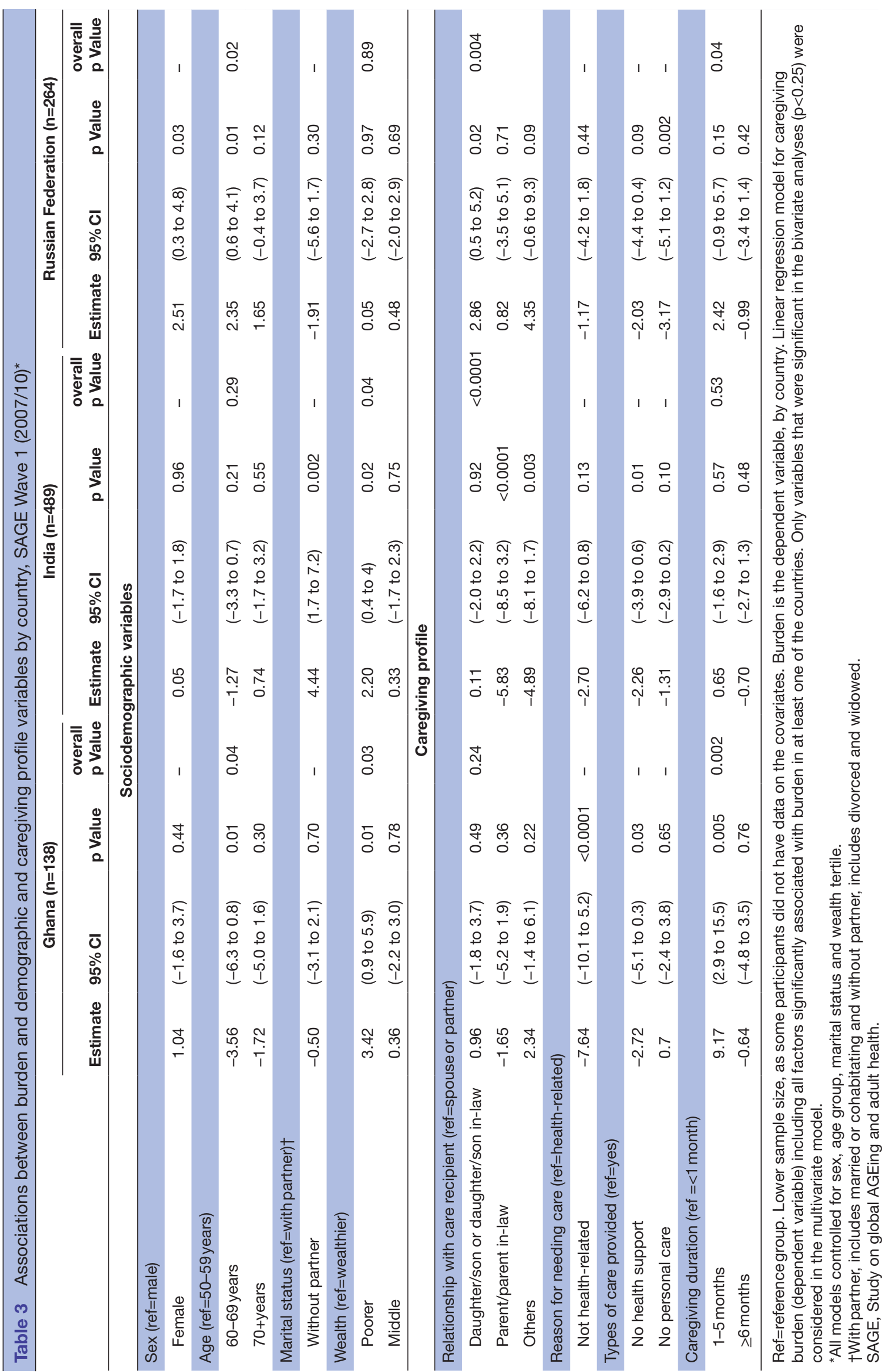

$\stackrel{\infty}{3}$

응

$\overrightarrow{\bar{F}}$

음

$\frac{0}{\sqrt{0}}$ 


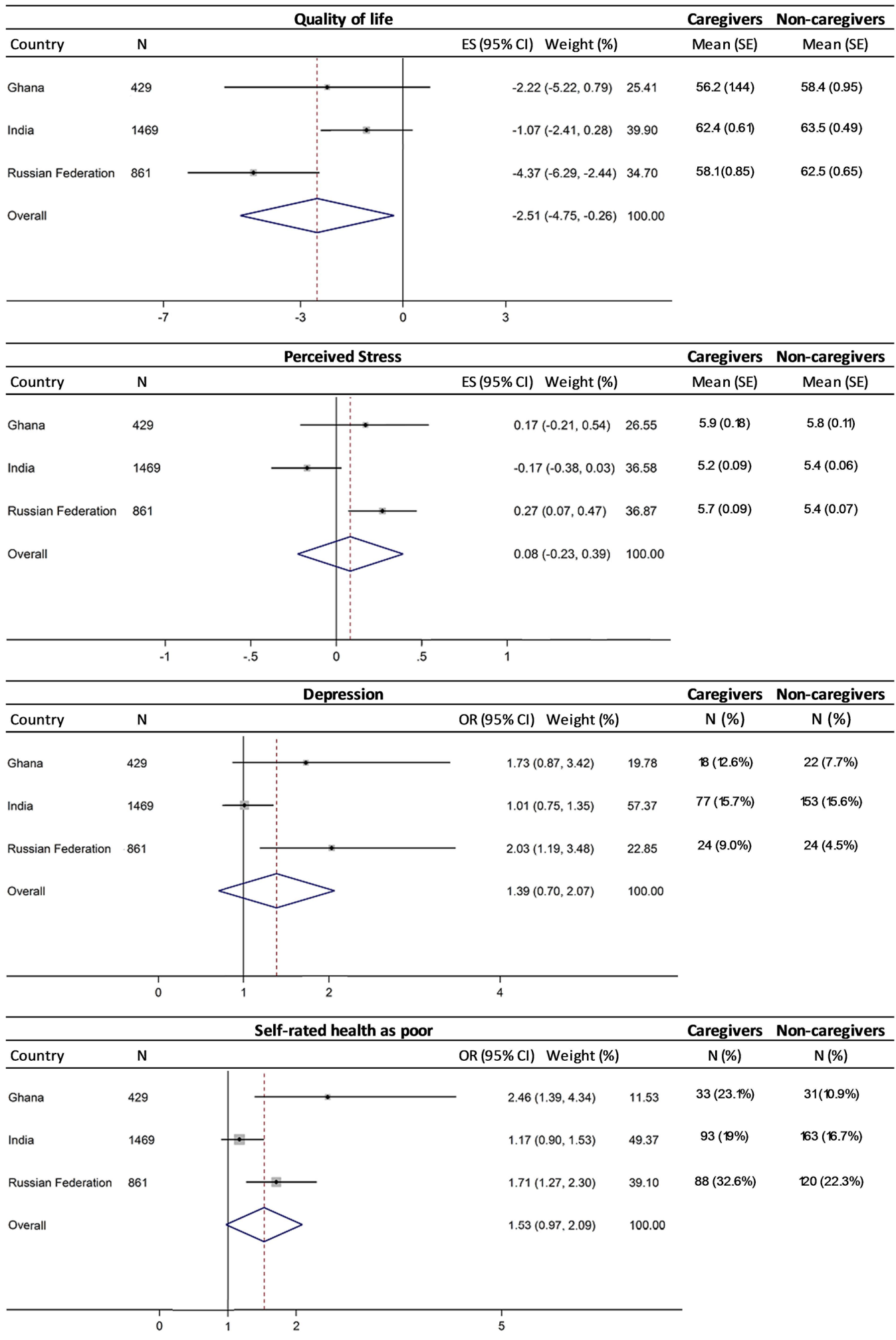

Figure 1 Comparison of health-related outcomes between caregivers and non-caregivers (matched controls) by country, SAGE Wave 1 (2007/10). ES, effect size; SAGE, Study on global AGEing and adult health.

personal care: bathing, dressing and toileting, which are known sources of strain for caregivers.

Similar to studies in HICs, ${ }^{7}$ findings of this secondary analysis emphasised that caregiving in two LMICs and one upper-middle income country is not without consequences on the level of burden reported. The lack of a clear pattern of associations among demographic and caregiving profile variables and burden emphasised the need for a tailored approach to policy and service development by country. Despite this variation, findings 


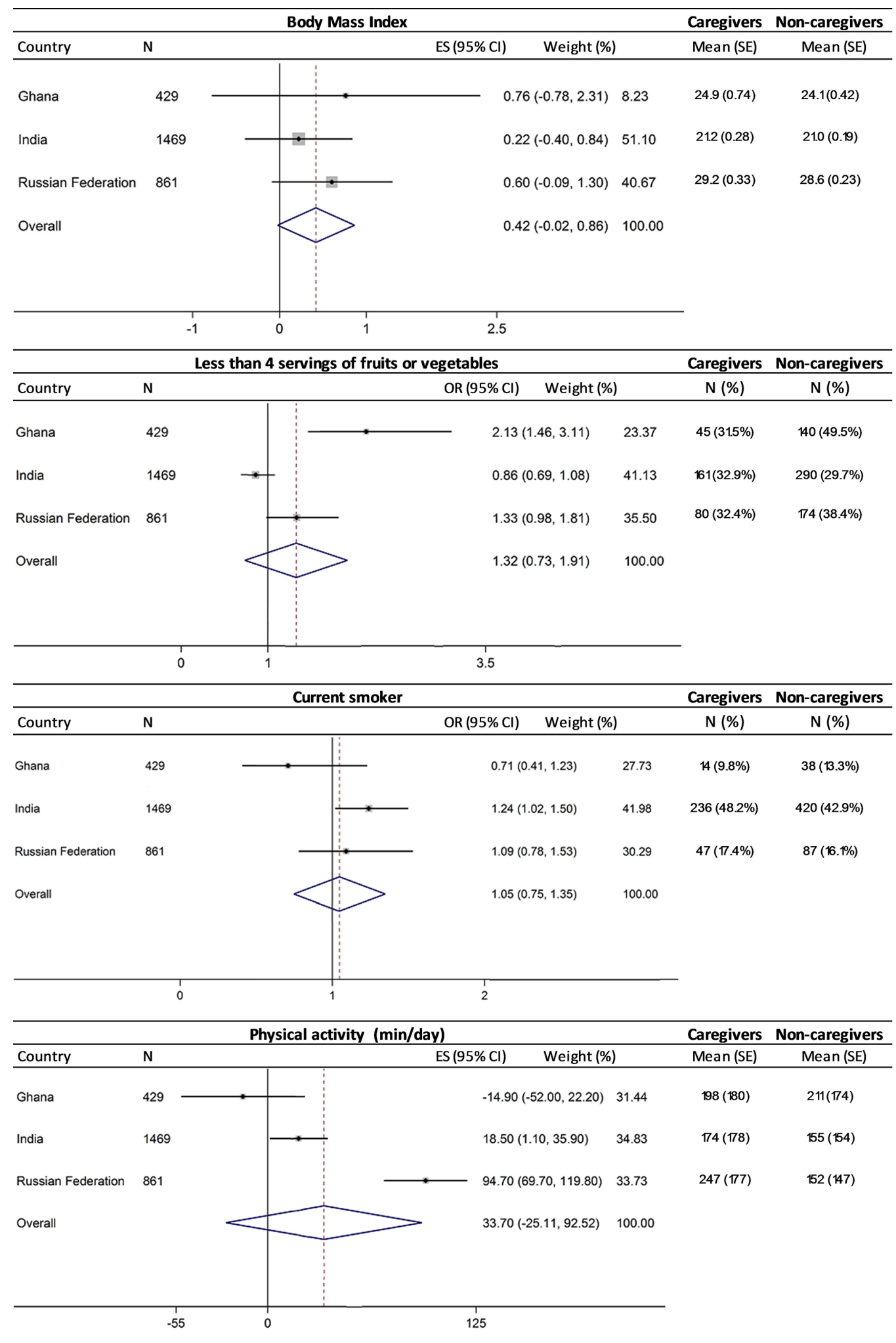

Figure 2 Comparison of health risk factors between caregivers and non-caregivers (matched controls) by country, SAGE Wave 1 (2007/10). ES, effect size; SAGE, Study on global AGEing and adult health.

are mostly consistent with studies in HICs. ${ }^{7}$ This means that low-cost, evidence-based, caregiver programmes (e.g., self-directed coping skills programmes) developed in HICs might be amenable to the context found in LMICs and upper-middle income countries, following appropriate adaptations. Although only significant in Russia, many studies have corroborated the high burden among female caregivers. ${ }^{75}$ Similar to the contradictory findings on age across Ghana and Russia, some studies have reported that younger caregivers have multiple 


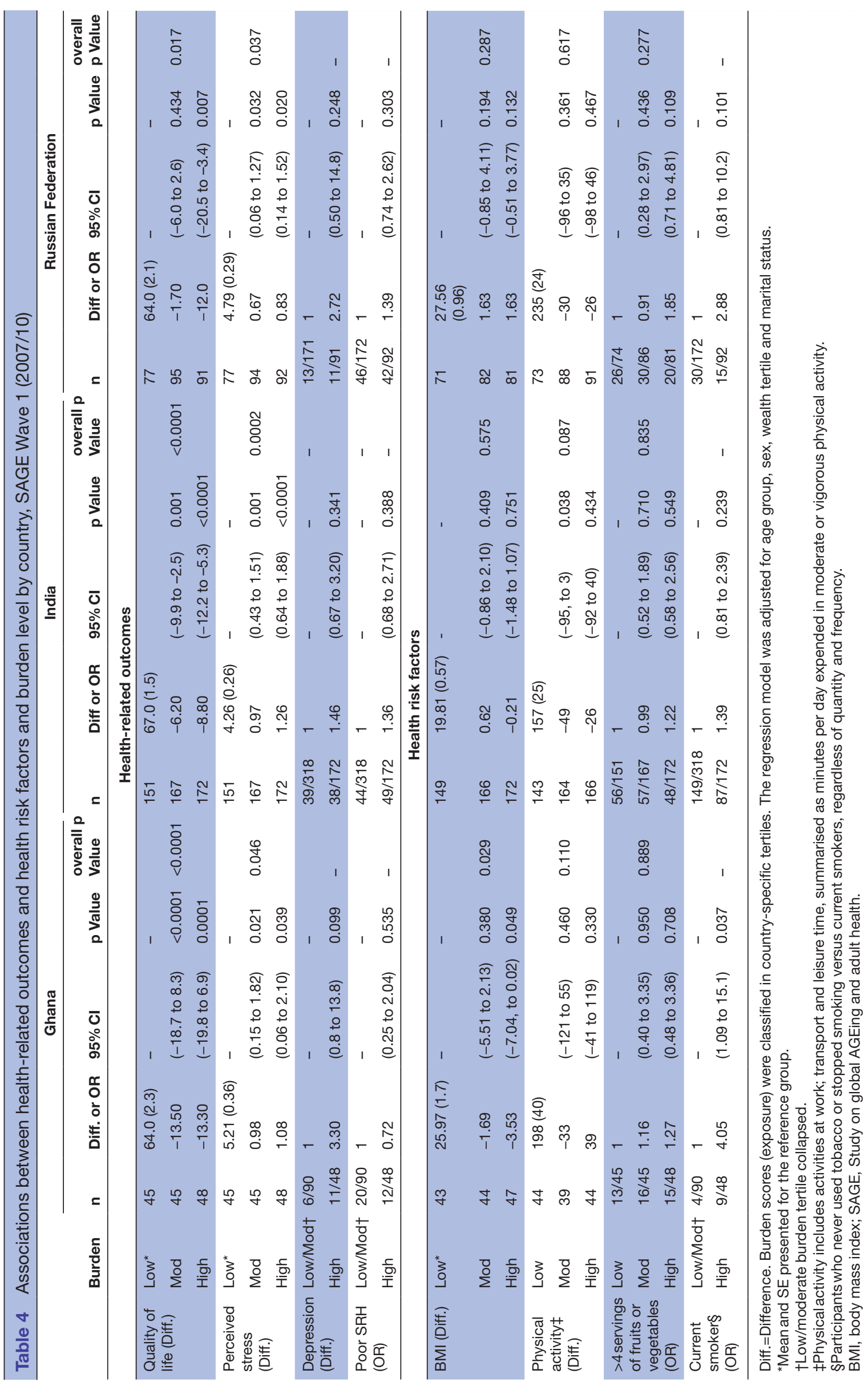


competing demands and are thereby more at risk of burden, whereas others have found that as older adults are coping with their own declining health, they are more at risk of burden. ${ }^{7}$ The higher burden associated with the marital status 'without partner' in India is similar to a study in Ethiopia ${ }^{46}$ and might indirectly emphasise the lack of support this caregiver subgroup receives. The findings pertaining to wealth in Ghana and India are consistent with studies in HICs associating lower income to high caregiver burden. ${ }^{7}$ Previous studies ${ }^{538}$ also substantiated the impact of the type of relationship to the care recipient on caregiver outcomes, with particular vulnerable subgroups confirmed in the present analysis, including adult children. ${ }^{76}$ Adult children are 'sandwiched' between raising their own children and providing for their family as well as taking on additional caregiving responsibilities. However, this is a growing group of caregivers, because of the overall ageing of the population. Spouses have been found to be at particular risk of financial burden, ${ }^{46}$ which might explain findings in India. Beyond relationship type, Pinto et $a t^{47}$ found that the quality of the relationship was more associated with burden than were variables such as gender, marital status and illness severity. Although household size has been found to be positively associated with caregivers' emotional distress, ${ }^{48}$ it was not a significant variable in the multivariate model. One reason for this is that a global measure of burden was used and household size might have an impact on different dimensions of burden.

One of the most common consequences of caregiving burden is poor QOL and mental health problems such as stress and depression. ${ }^{15}$ Our finding that burden adversely impacted on caregivers' QOL has only been reported by one other LMIC study. ${ }^{47}$ In this study, among the domains of QOL, general health received the lowest score. The present study is the only one to document that caregivers reported lower QOL than non-caregivers, representing a vulnerable segment of the population. A finding further strengthened by the one that caregivers were also more likely to rate their health as poor in comparison to non-caregivers. Although perceived stress did not differ between caregivers and non-caregivers, across countries, caregivers' burden was positively associated with this outcome. Only one other LMIC study was found to report on caregivers' stress, finding that $39 \%$ of older caregivers in Zimbabwe reported chronic stress. ${ }^{49}$ A concern is that stress can lead to other emotional and/ or physical problems such as insomnia, headaches and depression for caregivers and compromise their ability to sustain caregiving. ${ }^{50}$

Studies in HICs have found that caregivers report more unhealthy behaviours after taking on their role, such as low fruit and vegetable intake, increased use of tobacco, low PA and being overweight. ${ }^{7}$ No comparable study in LMICs was found. In the present study, few significant findings were noted for the relationship between level of burden and health risk factors. The significant finding between smoking and burden in Ghana is in line with findings from Beesley et al ${ }^{12}$ reporting that $10 \%$ of caregivers of women with ovarian cancer were smokers and $54 \%$ did not meet the guidelines for PA and $37 \%$ consumed more than two alcoholic beverages per occasion.

\section{Strengths and weaknesses of the study}

This is the first comprehensive study on informal caregiving burden among two LMICs and one upper-middle income country. Key strengths include that SAGE has nationally representative samples and high response rates. ${ }^{25}$ One weakness of this survey is related to its interview length ${ }^{25}$ and this burden might have affected the quality of the responses to the caregiving-related questions as these were the last section of the interview. Also, the sample size of the primary SAGE study was determined by the country specific teams and the sample size for the secondary analysis is limited to those who completed the Impact of Caregiving section. There is no information about how many participants were caregivers, but might have refused to complete this section. The questionnaire was created for the purpose of the primary SAGE study, with the burden scale developed by the World Health Survey team (details of the development process are not available). However, EFA of the burden scale in each country followed by reliability analysis have supported the key psychometric properties of the scales used in this secondary analysis. The cross-sectional design precludes causal inferences. Another limitation is that as the SAGE data were collected to assess the health of the participant completing the survey, but they were not asked about the health of the care recipient beyond what has been reported in this secondary analysis and the caregiver data cannot be linked to the care recipient (even if they also participated in the SAGE survey).

\section{CONCLUSION}

In contrast with the available evidence of the impact of caregiving in HICs, little is known about taking on this role in LMICs. The present comprehensive caregiver study is the first of its kind internationally that informs our understanding of caregivers in India, Ghana and Russia. Few caregivers reported receiving support to help them with their role. Variables associated with burden were country-specific, but commonly included wealth, type of care and caregiving duration, which is consistent with HIC studies. Across countries, burden had an adverse impact on caregivers' stress and QOL and caregivers reported lower QOL and SRH than non-caregivers. These findings contribute to the growing evidence base on the substantial burden endured by caregivers in LMICs and the consequences of this role on their health. The findings of this study, in combination with those of other studies, can facilitate advocacy efforts aimed at improving support for caregivers in LMICs and strengthen their capacity to sustain their role.

\section{Author affiliations}

${ }^{1}$ Ingram School of Nursing, McGill University, Montreal, Quebec, Canada 
${ }^{2}$ Faculty of Health, Deakin University, Geelong, Australia

${ }^{3}$ Department of Anthropology, University of Oregon, Geneva, Switzerland

${ }^{4}$ Research Centre for Generational Health and Ageing, University of Newcastle,

Newcastle, New South Wales, Australia

${ }^{5}$ St. Mary's Research Centre, St. Mary's Research Centre, Montreal, Quebec, Canada

Contributors All authors have made substantial contributions to (1) the conception of this secondary analysis study (SL, LO, SB, PML, LH), data analysis (LO, SL, SC) and/or interpretation of data (SL, LO, SB, PML, LH, PK) and (2) drafting the article (SL, LO) and/or revising it critically (SB, PML, LH, PK, SC). All authors have read and approved the final version of the manuscript and agreed to be accountable for all aspects of this study.

Funding SL was supported by a Deakin University Thinkers /Industry Expert in Residence Program and by a FRQS Junior 1 Research Scholar Award initially and then by a Canada Research Chair (Tier 2). SAGE was funded by WHO, the US National Institute on Aging through Interagency Agreements (OGHA 04034785; YA1323-08-CN-0020; Y1-AG-1005-01) and research grant (R01-AG034479); and Science and Technology Commission of Shanghai Municipality (Grant No. 10XD1403600).

\section{Competing interests None declared.}

Ethics approval SAGE received approval from the WHO's Ethical Review Committee and the respective committees in each participating country. Written informed consent was obtained from all study participants. For this secondary data analysis, ethical clearance was obtained from Deakin University.

Provenance and peer review Not commissioned; externally peer reviewed.

Data sharing statement № additional data available.

Open Access This is an Open Access article distributed in accordance with the Creative Commons Attribution Non Commercial (CC BY-NC 4.0) license, which permits others to distribute, remix, adapt, build upon this work non-commercially, and license their derivative works on different terms, provided the original work is properly cited and the use is non-commercial. See: http://creativecommons.org/ licenses/by-nc/4.0/

(C) Article author(s) (or their employer(s) unless otherwise stated in the text of the article) 2017. All rights reserved. No commercial use is permitted unless otherwise expressly granted.

\section{REFERENCES}

1. United Nations Department of Economic and Social Affairs Population Division. World population ageing 2015. ST/ESA/ SER.A/390.

2. Prince MJ, Wu F, Guo Y, et al. The burden of disease in older people and implications for health policy and practice. Lancet 2015;385:549-62.

3. Knickman JR, Snell EK. The 2030 problem: caring for aging baby boomers. Health Serv Res 2002;37:849-84.

4. Institute of Medicine (IOM). Retooling for an Aging America: Building the Health Care Workforce, 2008.

5. Caregiver assessment: principles, guidelines and strategies for change. Report from a national consensus development conference. San Francisco, CA: Family Caregiver Alliance, 2006.

6. Trujillo AJ, Mroz TA, Piras C, et al. Caregiving and elderly health in Mexico. Int J Health Serv 2012;42:667-94.

7. Lambert SD, Girgis A, Levesque J. The impact of cancer and chronic conditions on caregivers and family members. In: Koczwara $\mathrm{B}$, ed. Cancer and chronic conditions: addressing the problem of multimorbidity in cancer patients and survivors. springer Science+Business Media, 2016

8. Kim Y, Schulz R. Family caregivers' strains: comparative analysis of cancer caregiving with dementia, diabetes, and frail elderly caregiving. J Aging Health 2008;20:483-503.

9. Wolff JL. Family matters in health care delivery. JAMA 2012;308:1529-30

10. Cepoiu-Martin M, Tam-Tham H, Patten S, et al. Predictors of longterm care placement in persons with dementia: a systematic review and meta-analysis. Int J Geriatr Psychiatry 2016;31:1151-71.

11. Stenberg $U$, Ruland CM, Miaskowski $C$. Review of the literature on the effects of caring for a patient with cancer. Psychooncology 2010;19:1013-25.
12. Beesley VL, Price MA, Webb PM. Australian Ovarian Cancer Study GroupAustralian Ovarian Cancer Study-Quality of Life Study Investigators. Loss of lifestyle: health behaviour and weight changes after becoming a caregiver of a family member diagnosed with ovarian cancer. Support Care Cancer 2011;19:1949-56.

13. Aldrich N. CDC seeks to protect health of family caregivers. National Association of Chronic Disease (CDC), 2011.

14. Canadian Institutes of Health Research (CIHR). Pan-Canadian vision and strategy for health services and policy research 2014-2019, 2015.

15. Thrush A, Hyder AA, Hyder A. The neglected burden of caregiving in low- and middle-income countries. Disabil Health $\mathrm{J}$ 2014;7:262-72.

16. World health Organization. World report on disability, 2011.

17. Marten R, Mclntyre D, Travassos C, et al. An assessment of progress towards universal health coverage in Brazil, Russia, India, China, and South Africa (BRICS). The Lancet 2014;384:2164-71.

18. World Health Organization. Secondary Ghana 2017. Ghana. http:// www.who.int/countries/gha/en/

19. Canadian Institute for Health Information. National health expenditure trends, 1975 to 2016. Ottawa: ON, 2016.

20. National Center for Health Statistics. Health, United States, 2015 with special feature on racial and ethnic health disparities, 2016

21. Ke X, Saksena P, Holly A. The determinants of health expenditure: a country-level panel data analysis. Geneva: World Health Organization, 2011.

22. Yip W, Mahal A. The health care systems of China and India: performance and future challenges. Health Aff 2008;27:921-32.

23. Beaglehole R, Epping-Jordan J, Patel V, et al. Improving the prevention and management of chronic disease in low-income and middle-income countries: a priority for primary health care. Lancet 2008;372:940-9.

24. Mclntyre D, Thiede M, Dahlgren G, et al. What are the economic consequences for households of illness and of paying for health care in low- and middle-income country contexts? Soc Sci Med 2006;62:858-65.

25. Kowal P, Chatterji S, Naidoo N, et al. Data resource profile: the World Health Organization Study on global AGEing and adult health (SAGE). Int J Epidemiol 2012;41:1639-49.

26. Naidoo N. SAGE Working Paper No. 5. WHO Study on global AGEing and adult health (SAGE) Waves 0 and 1 - Sampling information for China, Ghana, India, Mexico, Russia and South Africa. Geneva: WHO, 2012.

27. United Nations Educational SaCOU. International Standard Classification of Education (ISCE) 1997, 2006.

28. Howe LD, Galobardes B, Matijasevich A, et al. Measuring socioeconomic position for epidemiological studies in low- and middleincome countries: a methods of measurement in epidemiology paper. Int J Epidemiol 2012:41:871-86.

29. Sanuade OA, Boatemaa S. Caregiver profiles and determinants of caregiving burden in Ghana. Public Health 2015;129:941-7.

30. Schmidt S, Mühlan H, Power M. The EUROHIS-QOL 8-item index: psychometric results of a cross-cultural field study. Eur $J$ Public Health 2006;16:420-8.

31. da Rocha NS, Power MJ, Bushnell DM, et al. The EUROHIS-QOL 8-item index: comparative psychometric properties to its parent WHOQOL-BREF. Value Health 2012;15:449-57.

32. Cohen S, Kamarck T, Mermelstein R. A global measure of perceived stress. J Health Soc Behav 1983;24:385-96.

33. Kessler RC, Ustün TB. The World Mental Health (WMH) Survey Initiative Version of the World Health Organization (WHO) Composite International Diagnostic Interview (CIDI). Int J Methods Psychiatr Res 2004;13:93-121.

34. World Health Organization. The ICD-10 classification of mental and behavioural disorders: diagnostic criteria for research (DCR-10). Geneva, Switzerland: World Health Organization, 1993.

35. Kulkarni RS, Shinde RL. Depression and Its Associated Factors in Older Indians: A Study Based on Study of Global Aging and Adult Health (SAGE)-2007. J Aging Health 2015;27:622-49.

36. Hirve S, Juvekar S, Sambhudas S, et al. Does self-rated health predict death in adults aged 50 years and above in India? Evidence from a rural population under health and demographic surveillance. Int J Epidemiol 2012;41:1719-27.

37. World Health Organization. Body mass index - BMI. 2016. http:// www.euro.who.int/en/health-topics/disease-prevention/nutrition/ahealthy-lifestyle/body-mass-index-bmi

38. Bull FC, Maslin TS, Armstrong T. Global physical activity questionnaire (GPAQ): nine country reliability and validity study. $J$ Phys Act Health 2009;6:790-804.

39. American Heart Association. Fruits and Vegetables. 2016. http:// www.heart.org/HEARTORG/HealthyLiving/HealthyEating/Nutrition/ 
Fruit-and-Vegetable-Serving-Sizes-Infographic_UCM_468564_ SubHomePage.jsp

40. Health Canada. Canada's food guide - how much food you need every day. 2007. http://www.hc-sc.gc.ca/fn-an/food-guide-aliment/ basics-base/quantit-eng.php

41. Anand A, Roy N. Prevalence and determinants of co-use of alcohol and tobacco among men in working age group (18-59 years) in India. Epidemiol Biostat Public Health 2016;13:e11642.

42. DerSimonian R, Laird N. Meta-analysis in clinical trials. Control Clin Trials 1986;7:177-88.

43. Mwinituo PP, Mill JE. Stigma associated with Ghanaian caregivers of AIDS patients. West J Nurs Res 2006;28:369-82. discussion 8391.

44. Pharr JR, Dodge Francis C, Terry C, et al. Culture, caregiving, and health: exploring the influence of culture on family caregiver experiences. ISRN Public Health 2014;2014:1-8.
45. Thara R, Kamath S, Kumar S. Women with schizophrenia and broken marriages-doubly disadvantaged? Part II: family perspective. Int $J$ Soc Psychiatry 2003;49:233-40.

46. Shibre T, Kebede D, Alem A, et al. Schizophrenia: illness impact on family members in a traditional society-rural Ethiopia. Soc Psychiatry Psychiatr Epidemiol 2003;38:27-34

47. Pinto RA, Holanda MA, Medeiros MM, et al. Assessment of the burden of caregiving for patients with chronic obstructive pulmonary disease. Respir Med 2007;101:2402-8.

48. Yusuf AJ, Nuhu FT. Factors associated with emotional distress among caregivers of patients with schizophrenia in Katsina, Nigeria. Soc Psychiatry Psychiatr Epidemiol 2011;46:11-16.

49. Organization WH. Impact of AIDS on older people in Africa: Zimbabwe case study. Geneva, Switzerland: Non-communicable Disease Prevention and Health Promotion, 2002.

50. Schulz R, Sherwood PR. Physical and mental health effects of family caregiving. Am J Nurs 2008;108(9 Suppl):23-7. 